\title{
Prophylaxis and Treatment of Cancer-Associated Venous Thromboembolism - Comparison Hematologist/ Oncologists versus Angiologist/Phlebologists
}

\author{
Axel Matzdorffa Bettina Ledig ${ }^{b}$ Markus Stücker ${ }^{c}$ Hanno Riess $^{d}$ \\ a Dpt. Of Internal Medicine II, Asklepios Clinic Uckermark, Schwedt/Od., Germany; \\ b LEO Pharma GmbH, Neu-Isenburg, Germany; \\ c Department of Dermatology, St. Josef Hospital, Ruhr-University of Bochum, Bochum, Germany; \\ d Medical Clinic Haematology/Oncology, Charité Campus Virchow-Clinic, Berlin, Germany
}

\section{Keywords}

Cancer-associated venous thromboembolism . Health services research · Hematologist - Oncologist . Angiologist . Phlebologist

\section{Dear Editor,}

In 2016, we published a survey on the prophylaxis and treatment of cancer-associated venous thromboembolism (VTE) in this journal [1]. The survey showed that practice patterns often do not follow guideline recommendations with respect to the use of low molecular weight heparin (LMWH) for the long-term treatment of VTE in cancer patients. This is a subgroup analysis comparing the 2 largest groups of respondents: hematologist/oncologists versus angiologist/phlebologists. It does not show significant differences in the treatment of acute VTE but in the secondary anticoagulant prophylaxis 3-6 months after acute VTE.

Cancer patients have a 4-7-fold higher risk of VTE than noncancer patients $[2,3]$. This is due to numerous risk factors, e.g. surgery, immobility, advanced age, prothrombotic medications, and coagulation activation by the tumor itself. Several guidelines on the prophylaxis and treatment of cancer-associated VTE have been published [4-7]. They uniformly recommend that VTE prophylaxis should be given to all cancer patients hospitalized with an acute illness, while for outpatients routine thromboprophylaxis is not recommended but under active discussion and investigation. For the treatment of established acute VTE, cancer patients should be given LMWH, both initially and long-term (first 3-6 months), while non-cancer patients are usually switched to a vitamin $\mathrm{K}$ antagonist (VKA) or a non-vitamin $\mathrm{K}$ new oral anticoagulant (NOAC) for secondary prevention. The use of NOACs is currently not recommended for the first 3-6 months in patients with malignancy and VTE. Despite these recommendations, several studies indicate that the impact of VTE guidelines on clinical practice is limited $[8,9]$. We recently published a survey among physicians who treat cancer patients, which showed several deviations, in particular that hospitalized cancer patients often do not receive VTE prophylaxis and many cancer patients with established VTE receive VKAs or NOACs [1]. Cancer patients with a VTE are seen by many different medical specialists, e.g. their family physician, hematologist/oncologists, or angiologist/phlebologists. Here, we present a subgroup analysis to see whether there are differences in the approach to VTE in cancer patients among medical specialties.

The details of our survey have been published previously [1]. Briefly, a questionnaire was sent to all members of DGHO (Deutsche Gesellschaft für Hämatologie und Onkologie), BNHO (Berufsverband Niedergelassener Hämatologen und Onkologen), and DGP (Deutsche Gesellschaft für Phlebologie). 275 questionnaires (5.9\% of all sent) were returned and analyzed. The low response rate was discussed in the preceding publication [1]. While the survey results may not be representative, they are still hypothesis-generating.

The largest groups among the responding physicians were hematologist/oncologists $(\mathrm{n}=214,78.4 \%)$ and angiologist/phlebologists $(\mathrm{n}=34,12.5 \%)$; the remainder included internists (not hematologist/oncologists or angiologist/phlebologists), surgeons, radio-oncologists, and transfusion medicine specialists. Here, we compare hematologist/oncologists and angiologist/phlebologists (table 1). Cancer-associated VTE is a common problem both in hematology/oncology and in angiology/phlebology practice. For both the initial treatment of established VTE and secondary prophylaxis throughout the next 3-6 months, both specialties give primarily LMWH but a considerable percentage also switches to VKAs and

\section{KARGER}

() 2017 S. Karger GmbH, Freiburg 
Table 1. Responses of hematologist/oncologists and angiologist/ phlebologists to different aspects of venous thromboembolism (VTE) prophylaxis and treatment in cancer patients

\begin{tabular}{|c|c|c|c|}
\hline & $\begin{array}{l}\text { Angiologist/ } \\
\text { phlebologists, \% }\end{array}$ & $\begin{array}{l}\text { Hematologist/ } \\
\text { oncologists, \% }\end{array}$ & $\mathrm{p}$ \\
\hline $\begin{array}{l}\text { Cancer patients with suspected or newly diagnosed thrombosis/embolism are } \\
\text { a frequent issue in my practice/clinic (e.g. } 1 \text { patient per week or more). }\end{array}$ & 30.0 & 29.9 & N.S. \\
\hline $\begin{array}{l}\text { For the initial treatment of a newly diagnosed thrombosis in cancer patients, } \\
\text { I administer as a rule only low molecular weight heparin (LMWH). }\end{array}$ & 70.0 & 78.8 & N.S. \\
\hline $\begin{array}{l}\text { For secondary prophylaxis after acute VTE during the first 3-6 months, I } \\
\text { switch my cancer patients to another anticoagulant (vitamin K antagonist } \\
\text { (VKA), new oral anticoagulant (NOAC)). }\end{array}$ & & & N.S. \\
\hline No, I continue LMWH & 40.7 & 55.6 & \\
\hline Yes, to a VKA & 22.2 & 12.8 & \\
\hline Yes, to 1 of the NOACs & 18.5 & 17.8 & \\
\hline Yes, to either a VKA or a NOAC & 18.5 & 13.9 & \\
\hline $\begin{array}{l}\text { I intend to give anticoagulation treatment for thrombosis/embolism to my } \\
\text { cancer patients (LMWH and other anticoagulants taken together). }{ }^{\mathrm{a}}\end{array}$ & & & N.S. \\
\hline Up to 1 month & 3.7 & 3.0 & \\
\hline Up to 3 months & 11.1 & 32.7 & \\
\hline Up to 6 months & 51.9 & 59.9 & \\
\hline Longer than 6 months & 77.8 & 76.2 & \\
\hline $\begin{array}{l}\text { When you give anticoagulation, e.g. LMWH, for 3-6 months, do you reduce } \\
\text { the dose in the further course? }\end{array}$ & & & 0.026 \\
\hline I do not reduce & 56.5 & 36.6 & \\
\hline I reduce after 1 month & 13.0 & 21.1 & \\
\hline I reduce after 3 months & 8.7 & 32.6 & \\
\hline I reduce at another point in time & 21.7 & 9.7 & \\
\hline When LMWH is given for $3-6$ months, ${ }^{b}$ & & & 0.001 \\
\hline I do not reduce the dose and give $100 \%$ & 38.5 & 34.7 & \\
\hline I give $75 \%$ of the initial dose & 50.0 & 21.0 & \\
\hline I give $50 \%$ of the initial dose & 11.5 & 44.3 & \\
\hline $\begin{array}{l}\text { For permanent anticoagulation, i.e. beyond } 6 \text { months, do you as a rule put } \\
\text { your cancer patients on another anticoagulant (VKA/NOAC)? }\end{array}$ & & & N.S. \\
\hline No & 34.5 & 35.9 & \\
\hline Yes, on a VKA & 31.0 & 21.2 & \\
\hline Yes, on a NOAC & 10.3 & 21.8 & \\
\hline Either on a VKA or a NOAC & 24.1 & 21.2 & \\
\hline $\begin{array}{l}\text { Have you previously used a NOAC in cancer patients, not just for VTE but } \\
\text { also for other indications such as atrial fibrillation? }\end{array}$ & & & $<0.001$ \\
\hline No & 48.1 & 15.8 & \\
\hline
\end{tabular}

${ }^{\mathrm{a}}$ For this question, more than 1 answer was possible and the sum of percentages therefore exceeds $100 \%$.

${ }^{\text {b}}$ The percentage for 'I do not reduce' is not identical for these 2 questions because not all respondents marked both questions. N.S. $=$ Not significant.
NOACs. If hematologist/oncologists give LMWH for 3-6 months, they reduce the dose earlier than angiologist/phlebologists and prefer half-therapeutic doses. Beyond 6 months, there is no difference with regard to using LMWH or oral anticoagulants. Fewer angiologist/phlebologists reported to have previously prescribed NOACs to cancer patients (not only for VTE but also for other indications, e.g. atrial fibrillation). We can only speculate about the reasons for these differences:

Angiologist/phlebologists might be more familiar with VTE guideline recommendations than hematologist/oncologists since VTE is more central to their medical specialty, while in hematology/oncology practice this is only one of many issues.

More hematologist/oncologists than angiologist/phlebologists give secondary anticoagulant prophylaxis after acute VTE for only up to 3 months. For long-term treatment, angiologist/phlebologists prefer an LMWH dose of $75 \%$ (similar to the recommendation for dalteparin), while hematologist/oncologists often reduce the LMWH dose to 50\%. Hematologist/oncologists perform dose reductions earlier than angiologist/phlebologists. A possible reason for this could be that hematologist/oncologists are more concerned about the risk of bleeding which is particularly high in cancer patients. Shorter anticoagulation and half-therapeutic dosing 'feel' safer.

More angiologist/phlebologists than hematologist/oncologists stated they have not yet prescribed NOACs to cancer patients. Possible reasons could be that angiologist/phlebologists are more familiar with VTE guideline recommendations and might also be more focused on VTE treatment, while hematologist/oncologists 
see cancer patients not only for VTE but also for many other medical problems such as atrial fibrillation. In addition, cancer patients often take numerous medications at the same time. It could be that hematologist/oncologists prefer oral anticoagulants for cancer-associated VTE because they worry that their patients will not comply if prescribed yet 'another injection' in addition to antitumor and supportive care agents.

In conclusion, this study shows that angiologist/phlebologists follow guideline recommendations to a higher degree than hematologist/oncologists. In previous findings, we discovered that more than half of the hematologist/oncologists stated to transfer VTE care to the family physician, vascular medicine specialists, or other non-oncologists [1]. This is unfortunate because the incidence of cancer-associated VTE is comparable to that of febrile neutropenia after chemotherapy, and VTE is a leading cause of death in cancer patients [10]. A limitation of this survey is the low response rate (5.9\%) which is lower than usual for oncology surveys. The survey results might therefore not be representative but are still hypothesis-generating.

Over the last decade, hematology and oncology have been among the fastest growing specialties in medicine. Much of the attention in daily hematology/oncology practice is focused on new treatment strategies and new anticancer drugs, while the issue of anticoagulation for VTE prophylaxis and therapy seems to be of secondary importance. The awareness of VTE being not only a major cancer-associated but also sometimes treatment-dependent complication demands that the knowledge about standards and new developments in the prophylaxis and treatment of cancerassociated VTE must become a center of attention for all medical specialists who participate in the care of cancer patients.
Table 2. Recommendations for the treatment of venous thromboembolism (VTE) in patients with cancer [11]

Initial treatment of VTE: first 10 days of anticoagulation

1. Low molecular weight heparin (LMWH) is recommended.

2. Fondaparinux and unfractionated heparin can also be used.

Early maintenance (10 days to 3 months) and long-term (beyond 3 months)

1. LMWHs are preferred over vitamin $\mathrm{K}$ antagonists (VKAs).

2. LMWH should be used for a minimum of 3 months.

3. New oral anticoagulants (NOACs) can be considered for patients with stable cancer not receiving systemic anticancer therapy, and in cases where VKA is an acceptable but not available treatment choice.

4. After 3-6 months, termination or continuation of anticoagulation (LMWH, VKA, or direct oral anticoagulants) should be based on individual assessment.

On a final note, for educational purposes, we have added a table with the most recent treatment recommendations for cancer-associated VTE (table 2) [11].

\section{Disclosure Statement}

Matzdorff A: Stock ownership: Roche, Bayer; speakers honoraria and travel expenses: AMGEN, Aspen Germany, Boehringer Ingelheim, Behring, LEO Pharma, Roche; consultant fees: AMGEN, GlaxoSmithKline, Baxter, LEO Pharma, Boehringer Ingelheim, Bristol-Myers Squibb. Ledig B: Employee LEO Pharma. Stuecker M: Speakers honoraria from Bauerfeind and research funding from Bayer. Riess H: Consultant fees: Bayer, Boehringer Ingelheim, BMS, Daiichy-Sankyo, Leo Pharma; speakers honoraria: Bayer, Boehringer Ingelheim, BMS, Daiichy-Sankyo, LEO Pharma, Novartis, Pfizer, Sanofi-Aventis.

\section{References}

1 Matzdorff A, Ledig B, Stuecker M, Riess H: Practice patterns for prophylaxis and treatment of venous thromboembolism in German cancer patients. Oncol Res Treat 2016;39:194-201.

2 Heit JA, Silverstein MD, Mohr DN, Petterson TM, O'Fallon WM, Melton LJ 3rd: Risk factors for deep vein thrombosis and pulmonary embolism: a population-based case-control study. Arch Intern Med 2000 160:809-815.

3 Blom JW, Doggen CJ, Osanto S, Rosendaal FR: Malignancies, prothrombotic mutations, and the risk of venous thrombosis. JAMA 2005;293:715-722.

4 Lyman GH, Bohlke K, Khorana AA, Kuderer NM, Lee AY, Arcelus JI, Balaban EP, Clarke JM, Flowers CR, Francis CW, Gates LE, Kakkar AK, Key NS, Levine MN, Liebman HA, Tempero MA, Wong SL, Somerfield MR, Falanga A; American Society of Clinical Oncology: Venous thromboembolism prophylaxis and treatment in patients with cancer: American Society of Clinical Oncology Clinical Practice Guideline Update 2014. J Clin Oncol 2015;33:654-656.
5 NCCN Clinical Practice Guidelines in Oncology: Cancer-associated venous thromboembolic disease, version 1/2016. www.nccn.org (accessed 8/8/16).

6 Kearon C, Akl EA, Ornelas J, Blaivas A, Jimenez D, Bounameaux H, Huisman M, King CS, Morris TA, Sood N, Stevens SM, Vintch JR, Wells P, Woller SC, Moores L: Antithrombotic therapy for VTE disease: CHEST guideline and expert panel report. Chest 2016; 149:315-352.

7 Lee AY, Peterson EA, Wu C: Clinical practice guidelines on cancer-associated thrombosis: a review on scope and methodology. Thromb Res 2016;140(suppl 1):S119-S127.

8 Schellong SM, Gerlach H, Hach-Wunderle V, Rabe E, Riess H, Carnarius H, Eberle S, Bauersachs R: Diagnosis of deep-vein thrombosis: adherence to guidelines and outcomes in real-world health care. Thromb Haemost 2009;102:1234-1240.
9 Mahe I, Puget H, Buzzi JC, Lamuraglia M, Chidiac J, Strukov A, Helfer H, Perozziello A: Adherence to treatment guidelines for cancer-associated thrombosis: a French hospital-based cohort study. Support Care Cancer 2016;24:3369-3377.

10 Khorana AA, Francis CW, Culakova E, Kuderer NM, Lyman GH: Thromboembolism is a leading cause of death in cancer patients receiving outpatient chemotherapy. J Thromb Haemost 2007;5:632-634.

11 Farge D, Bounameaux H, Brenner B, Cajfinger F, Debourdeau P, Khorana AA, Pabinger I, Solymoss S, Douketis J, Kakkar A: International clinical practice guidelines including guidance for direct oral anticoagulants in the treatment and prophylaxis of venous thromboembolism in patients with cancer. Lancet Oncol 2016;17:e452-e466. 